\title{
Mechanical dispersion of clay from soil into water: readily-dispersed and spontaneously-dispersed clay
}

\author{
Ewa A. Czyżi,2* and Anthony R. Dexter ${ }^{2}$ \\ ${ }^{1}$ Department of Soil Science, Environmental Chemistry and Hydrology, University of Rzeszów, \\ Zelwerowicza 8b, 35-601 Rzeszów, Poland \\ ${ }^{2}$ Institute of Soil Science and Plant Cultivation (IUNG-PIB), Czartoryskich 8, 24-100 Puławy, Poland
}

Received July 1, 2014; accepted October 10, 2014

\begin{abstract}
A b s t r a c t. A method for the experimental determination of the amount of clay dispersed from soil into water is described. The method was evaluated using soil samples from agricultural fields in 18 locations in Poland. Soil particle size distributions, contents of organic matter and exchangeable cations were measured by standard methods. Sub-samples were placed in distilled water and were subjected to four different energy inputs obtained by different numbers of inversions (end-over-end movements). The amounts of clay that dispersed into suspension were measured by light scattering (turbidimetry). An empirical equation was developed that provided an approximate fit to the experimental data for turbidity as a function of number of inversions. It is suggested that extrapolation of the fitted equation to zero inversions enables the amount of spontaneously-dispersed clay to be estimated. This method introduces the possibility of replacing the existing subjective, qualitative method of determining spontaneously-dispersed clay with a quantitative, objective method. Even though the dispersed clay is measured under saturated conditions, soil samples retain a 'memory' of the water contents at which they have been stored.

$\mathrm{K}$ e y w o r d s: clay dispersion, energy input, readily-dispersible clay, spontaneously-dispersed clay, turbidimetry
\end{abstract}

\section{INTRODUCTION}

Clay (defined as soil particles with an effective diameter of less than $2 \mu \mathrm{m}$ ) is arguably the most important component of soil. Even in sandy soils, the clay component is responsible for most of the surface area of the particles and therefore for most of the exchange sites that control adsorbed chemical species. Clay is a colloid (from the Greek word ' $\kappa \circ \lambda \lambda \alpha$ ' meaning 'glue') and often plays an important role in the gluing together of larger soil particles and thereby making the assemblage mechanically stable.
Clay particles can either flocculate or disperse in aqueous solution. When flocculation occurs, the particles combine to form larger, compound particles such as soil microaggregates. When dispersion occurs, the particles separate in suspension due to their electrical charge. Clay flocculationleads to soils thatare considered to bestable in water whereas dispersion is associated with soils that are considered to be unstable in water. We may note that this terminology is the opposite of that used in colloid science where the terms 'stable' and 'unstable' are used in relation to the suspensions (ie a stable suspension is one that is permanently dispersed and in which no flocculation is occurring).

Soil chemistry also affects clay dispersion/flocculation. Soils that are sodic (have a large content of exchangeable sodium) are dispersive, whereas soils that have large contents of exchangeable calcium tend to flocculate. The effects of sodicity on clay dispersion and reduction of soil hydraulic conductivity have been discussed by Quirk (1986).

Dispersed clay is mobile in the environment. For example, it can move across the soil surface with run-off water or it can move downwards in the soil profile with infiltrating water. The clay, when mobilized in the environment, can transport adsorbed pollutants. When rain falls on the soil surface, it can be considered as being essentially pure and clay can disperse spontaneously into suspension in it. However, as it moves downwards in the soil profile, it accumulates salts that dissolve out of the soil, and therefore its electrolyte concentration rises. Electrolyte concentration is conveniently measured as the electrical conductivity (EC). At a certain depth, which is different for different soils, the EC reaches a critical value at which flocculation occurs. 
At this stage, the clay is no longer mobile but becomes attached to and part of the surrounding soil. This is the process of illuviation which results in the formation of clay skins or cutans on soil aggregates or crack surfaces, and in the formation of clay-rich B horizons. By this process, soil profiles can be modified or formed. In this way, clay dispersion can be an important process in pedogenesis.

Dispersed clay can also have practical consequences in agriculture and in the environment. To determine the content of dispersible clay in soil, a known mass of soil (usually 4-5 g) is placed in water and subjected to a standard, small input of mechanical energy. The amount of clay dispersed in this way is called the readily-dispersible clay (RDC). When wet, soil in which much of the clay is RDC may collapse with the loss of larger pores and homogenization of the soil structure. This can result in a range of agricultural and environmental problems which include anaerobic soil which is not suitable for plant growth and reduced water infiltration rates which can result in increased water runoff, erosion and flooding (Brubaker et al., 1992). When dry, soils containing dispersible clay can form surface crusts orcan 'hard-set' which can preventcropemergenceand which can increase the energy requirement for tillage. The tensile strength of soil when dry is a good measure of hard-setting, and this is approximately proportional to the amount of RDC that was present before drying (Chan, 1989; Kay and Dexter, 1992; Shanmuganathan and Oades, 1982; Watts etal., 1996c). Similarly, the soil friability is smaller when more RDC is present (Dexter and Watts, 2000; Shanmuganathan and Oades, 1982). Negative correlations between the content of RDC and other measures of soil physical quality of have been discussed by Gațe et al. (2004) and Vizitiu et al. (2010).

The content of RDC is not constant for a given soil but is a dynamic property that can change significantly with many factors. Increased content of organic matter in soil has been found to reduce the amount of RDC in a Polish soil (Dexter and Czyż, 2000a), in Romanian soils (Watts et al., 1996b), and for a UK soil (Watts and Dexter, 1997). Tillage or other inputs of mechanical energy to soil increases the amount of RDC (Czyż and Dexter, 2009; Czyż and Vizitiu, 2012 ;Watts et al., 1996a,c) and this effect is greater when soil is wetter. The amount of RDC in a soil decreases as soil dries (Caron et al.,1992; Dexter et al., 2011). This is consistent with the finding that the content of RDC in moist soils collected from the field was 20 times greater than that of the same soils after air-drying (Czyż et al., 2010). This effect also explains the observed greater stability of soil after freezing in terms of freezing-induced soil desiccation (Dagesse, 2013). The content of RDC may also be changed (in either direction) by the history of wetting and drying of the soil (Dexter et al., 2011; Kay and Dexter, 1992).

Some clay is released from soil even with no input of mechanical energy. Such clay is called spontaneouslydispersed clay (SDC). A problem with its measurement is that any attempt to collect it unavoidably involves some mechanical disturbance which can have the result of releasing clouds of RDC from the soil sample which prevent meaningful measurement of SDC.

In order to clarify the terminology that we are using, we can note that the total clay (TC) is the same as is measured in the determination of soil particle size distributions as required for soil classification; the readily-dispersed clay (RDC) is that part of the $T C$ that becomes dispersible after a standard, small input of mechanical energy; and the spontaneously-dispersed clay is that part of the RDC that is dispersible with zero input of mechanical energy. Therefore,

$$
T C \geq \mathrm{RDC} \geq \mathrm{SDC}
$$

Both RDC and SDC are parts of the mechanically-dispersible clay (MDC).

Perhaps the most commonly-used method for assessing spontaneously-dispersed clay is the Emerson test (Emerson, 1967; Loveday and Pyle, 1973) which is used as the basis for standard methods in Australia (AS, 2006) and in the USA (ASTM, 2014). Although this method is widely-used, it suffers from the disadvantage of requiring subjective, qualitative assessments of the amount of dispersion, and it therefore requires considerable operator training and experience. In particular, the amount of clay being released by a soil sample has to be assessed in terms of the observed 'milkiness' of the suspension around the sample.

In this paper, we use the term 'turbidity' (from the Latin word 'turbidus' meaning 'crowd') instead of 'milkiness', and we measure this using a turbidimeter (Czyż and Dexter, 2011). In this way, we replace subjective, qualitative assessments with accurate quantitative measurements. A major advantage of the type of turbidimeter that we used is the huge range of turbidities (or concentrations) that can be measured (about 10000:1). Concentrations can be measured that are far below the lower limits of normal gravimetric or hydrometer methods. An example of the measurement of very small values of turbidity is given by the analysis of drainage water from lysimeters by Dexter and Czyż (2000b). It has been found that the concentration of clay in suspension ( $\left.\mathrm{eg} \mathrm{in} \mathrm{g} \mathrm{l}^{-1}\right)$ is directly proportional to the turbidity $T$ reading in NTU (nephelometric turbidity units) as read from the turbidimeter (Czyż et al., 2002; Watts et al., 1996a). The term 'nephelometric' comes from the Greek word ' $v \varepsilon \varphi \varepsilon ́ \lambda \eta$ ' meaning 'cloud'. A calibration equation obtained by Czyż et al. (2002) using data from both turbidimeter and hydrometer methods was:

$$
\text { clay }=(0.186 \pm 0.008) T \text {, }
$$

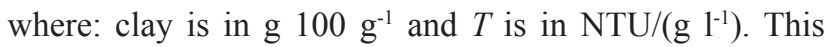
was the mean from 210 Polish soils although we note that for the most accurate work, every soil requires a separate calibration equation. 
In the following, we examine the effect of input of mechanical energy on the amount of clay dispersed from soil, and then use this result to predict the amount of clay dispersed with zero energy input which is the spontaneously-dispersed clay content of the soils. Effects of the water content at which soil samples are stored are also investigated.

\section{MATERIALS AND METHODS}

Soil samples were collected from the 0-200 mm layer of arable soils in Poland. This is within the layer that is tilled and therefore mixed annually. The samples were collected at or close to harvest which is typically in July. This gave the soil several months to settle after the tillage and sowing operations. Any obvious wheel tracks were avoided during soil sampling. Table 1 gives the positions of the sampling points as latitude and longitude. The profile numbers given in Table 1 are given to be consistent with another, larger, experiment (Czyż et al., 2002). The samples were stored in sealed plastic bags and were kept at their field water content until measurement.

Sub-samples were analyzed in the laboratory to obtain the particle size distribution, and the contents of organic carbon, exchangeable base cations $\left(\mathrm{Ca}^{++}, \mathrm{Mg}^{++}, \mathrm{K}^{+}\right.$and $\mathrm{Na}^{+}$) and gravimetric water content. The measurements were made using standard laboratory methods (ie sedimentation by the hydrometer method, wet oxidation, atomic absorption spectroscopy and oven drying).

The experimental procedure for determining the content of dispersible clay was as follows:

- a 4-5 g sub-sample was taken from each sample and weighed. The sample was then placed in a $150 \mathrm{ml}$ plastic bottle with minimum disturbance.

- the bottle was then filled to the $125 \mathrm{ml}$ level with distilled water. A constant volume of air bubble, which in this case is $25 \mathrm{ml}$, is essential to ensure constant energy input during inversion of the bottles.

T a b l e 1. Experimental soils: locations, compositions, organic carbon contents, contents of exchangeable cations and gravimetric water contents (note: to convert from Equivalents to Coulombs. use $1 \mathrm{mEq}=96.5 \mathrm{C}$ )

\begin{tabular}{|c|c|c|c|c|c|c|c|c|c|c|c|}
\hline \multirow{2}{*}{$\begin{array}{l}\text { Profile } \\
\text { number }\end{array}$} & Latitude & Longitude & Sand & Silt & Clay & $\mathrm{OC}$ & $\mathrm{Ca}^{++}$ & $\mathrm{Mg}^{++}$ & $\mathrm{K}^{+}$ & $\mathrm{Na}^{+}$ & $w$ \\
\hline & \multicolumn{2}{|c|}{$\left({ }^{\circ}\right)$} & \multicolumn{4}{|c|}{$\left(\mathrm{g} 100 \mathrm{~g}^{-1}\right)$} & \multicolumn{4}{|c|}{$\left(\mathrm{mEq} 100 \mathrm{~g}^{-1}\right)$} & $\left(\mathrm{g} 100 \mathrm{~g}^{-1}\right)$ \\
\hline 35 & 54.02917 & 21.86111 & 58 & 28 & 14 & 0.68 & 37.32 & 1.12 & 0.75 & 0.26 & 14.5 \\
\hline 37 & 54.12500 & 23.48194 & 69 & 25 & 6 & 1.07 & 3.37 & 0.48 & 0.28 & 0.03 & 12.5 \\
\hline 85 & 53.61944 & 21.85833 & 89 & 8 & 3 & 2.55 & 2.00 & 0.21 & 0.23 & 0.03 & 11.3 \\
\hline 89 & 53.08750 & 22.48611 & 75 & 19 & 6 & 0.60 & 2.37 & 0.33 & 0.34 & 0.13 & 17.8 \\
\hline 171 & 52.03333 & 23.07778 & 61 & 36 & 3 & 1.03 & 2.12 & 0.25 & 0.38 & 0.06 & 13.5 \\
\hline 173 & 52.05000 & 23.60139 & 72 & 26 & 2 & 1.33 & 1.75 & 0.33 & 0.34 & 0.06 & 9.8 \\
\hline 75 & 53.22917 & 20.00278 & 71 & 24 & 5 & 0.77 & 1.75 & 0.18 & 0.25 & 0.06 & 12.9 \\
\hline 145 & 52.99722 & 20.21111 & 78 & 18 & 4 & 0.75 & 1.50 & 0.16 & 0.30 & 0.06 & 7.2 \\
\hline 147 & 52.60833 & 20.40278 & 72 & 24 & 4 & 0.92 & 3.74 & 0.49 & 0.17 & 0.10 & 18.6 \\
\hline 149 & 52.75500 & 20.69500 & 85 & 14 & 1 & 0.70 & 1.12 & 0.11 & 0.08 & 0.03 & 14.9 \\
\hline 151 & 52.43750 & 20.78611 & 42 & 46 & 12 & 1.79 & 10.60 & 1.87 & 0.57 & 0.10 & 18.2 \\
\hline 153 & 52.15972 & 20.89444 & 70 & 25 & 5 & 0.90 & 1.37 & 0.14 & 0.29 & 0.03 & 15.6 \\
\hline 155 & 52.25139 & 21.32917 & 91 & 8 & 1 & 0.99 & 1.62 & 0.22 & 0.32 & 0.06 & 7.5 \\
\hline 157 & 52.20000 & 21.80278 & 85 & 12 & 3 & 0.89 & 1.87 & 0.23 & 0.17 & 0.03 & 10.4 \\
\hline 161 & 52.52778 & 22.04306 & 76 & 19 & 5 & 0.79 & 0.87 & 0.14 & 0.40 & 0.03 & 16.3 \\
\hline 163 & 52.10333 & 22.40556 & 70 & 25 & 5 & 0.99 & 1.12 & 0.19 & 0.28 & 0.03 & 15.9 \\
\hline 271 & 52.01389 & 21.55556 & 82 & 13 & 5 & 0.82 & 0.87 & 0.16 & 0.25 & 0.03 & 8.5 \\
\hline 273 & 51.87083 & 22.11528 & 80 & 17 & 3 & 0.86 & 0.62 & 0.14 & 0.32 & 0.03 & 9.9 \\
\hline
\end{tabular}

OC - organic carbon content, $w$ - water content 
- after about $5 \mathrm{~min}$, the bottle was inverted by hand to provide a reproducible energy input. This was always done by the same technician. The numbers of inversions used were $4,8,16$ and 32 .

- the bottles were then placed on the bench for sedimentation to proceed.

- after $16 \mathrm{~h}, 30 \mathrm{ml}$ of suspension was taken from the centre of each bottle by pipette and was transferred to a glass turbidimeter cell. This was done without movement of the plastic bottle which might have disturbed the sediment at the bottom of the bottle.

- the turbidity of the suspension was measured with a Hach 2100AN turbidimeter in NTU (Nephelometric Turbidity Units). This value was assumed to be proportional to the amount of clay in suspension as shown in Eq. (2).

Experiments were done with 5 replicates and here we report only the mean values. To get an idea of the natural variation of RDC values, we used experiments in which 10 replicates were measured for a further set of 18 soils. The mean coefficient of variation $(\mathrm{COV}=$ standard deviation as a proportion of the mean) of the RDC values was COV $=0.197$. We expect that the COV would be similar for the mean results presented here.

Estimation of the energy involved during one inversion of a bottle required measurement of the height $\left(h_{a}\right)$ of the air-bubble because this is the distance through which the $125 \mathrm{ml}$ (mass of water, $m_{w}=0.125 \mathrm{~kg}$ ) falls during one inversion. The energy $\left(E_{N}\right)$ involved in $N$ inversions of a bottle was estimated as follows:

$$
E_{N}=N m_{w} \mathrm{~g} h_{a}
$$

In our work on RDC done in Poland, we used $N=4$ inversions. Good soil physical quality was found for RDC $<1$, poor soil physical quality was found for $1<\mathrm{RDC}<2$, and very poor soil physical quality was found for $\mathrm{RDC}>2$, where the units are NTU/(g 1-1), (Czyż and Vizitiu, 2012). The above values are only approximate.

T a b l e 2. Experimental results for turbidities, $T$, after $N$ inversions and $T_{T C}$ for total clay

\begin{tabular}{|c|c|c|c|c|c|}
\hline \multirow{2}{*}{$\begin{array}{l}\text { Profile } \\
\text { number }\end{array}$} & \multicolumn{5}{|c|}{ Turbidity, $T$, (NTU/(g l-1)) } \\
\hline & $N=4$ & $N=8$ & $N=16$ & $N=32$ & $T_{T C}$ \\
\hline 35 & 6.199 & 10.719 & 14.241 & 22.444 & 81.537 \\
\hline 37 & 1.079 & 1.472 & 1.895 & 2.505 & 19.626 \\
\hline 85 & 0.385 & 0.549 & 0.614 & 0.722 & 4.893 \\
\hline 89 & 3.851 & 6.747 & 8.671 & 10.784 & 33.072 \\
\hline 171 & 1.240 & 1.616 & 1.720 & 2.387 & 16.685 \\
\hline 173 & 2.013 & 2.756 & 3.351 & 3.292 & 12.288 \\
\hline 75 & 2.191 & 2.829 & 3.326 & 3.734 & 19.523 \\
\hline 145 & 1.016 & 1.431 & 1.687 & 2.138 & 10.726 \\
\hline 147 & 4.180 & 6.976 & 8.089 & 9.435 & 23.912 \\
\hline 149 & 0.665 & 0.785 & 0.822 & 1.027 & 5.451 \\
\hline 151 & 4.541 & 7.155 & 10.528 & 15.812 & 77.222 \\
\hline 153 & 2.940 & 3.557 & 3.596 & 3.404 & 12.324 \\
\hline 155 & 0.500 & 0.595 & 0.663 & 0.730 & 2.921 \\
\hline 157 & 1.178 & 1.254 & 1.292 & 1.412 & 4.605 \\
\hline 161 & 1.552 & 2.213 & 1.937 & 1.932 & 9.085 \\
\hline 163 & 1.280 & 1.236 & 1.295 & 1.364 & 7.837 \\
\hline 271 & 1.353 & 1.357 & 1.765 & 2.030 & 9.295 \\
\hline 273 & 0.593 & 0.715 & 0.905 & 0.912 & 5.160 \\
\hline
\end{tabular}




\section{RESULTS AND DISCUSSION}

With the plastic bottles that we used, $h_{a}=18 \mathrm{~mm}$. This gives the value of $E_{1}$ as:

$$
E_{1}=0.022 \mathrm{~J} \text {, }
$$

From this, we may estimate the specific energy, $\Phi$ (energy per unit mass, $m_{d}$, of dry soil) as:

$$
\Phi_{1}=E_{1} / m_{d},
$$

If we assume that the mass of dry soil, $m_{d}=4 \mathrm{~g}$, then we get for $N=1$ :

$$
\Phi_{1}=5.5 \mathrm{~J} \mathrm{~kg}^{-1} .
$$

This gives, for the $N=4,8,16$ and 32 inversions used here: respectively.

$$
\Phi_{N}=22,44,88 \text { and } 176 \mathrm{~J} \mathrm{~kg}^{-1} \text {, }
$$

This value of specific energy may be compared with the energy required for soil tillage. This has been measured in terms of the drawbar pull or force, $F$, required to move a tillage implement of width, $w$, working at a depth $D$, over unit distance. This gives the energy involved in tilling a known volume of soil. This can be converted to the specific energy for tillage (energy per unit mass of soil) by dividing by the bulk density of the soil. Representative, measured values of the specific energy, $\Phi_{T}$, required for primary tillage with tynes, a mouldboard plough and a rotary tiller were found to be:

$$
\Phi_{T}=50,100 \text { and } 300 \mathrm{~J} \mathrm{~kg}^{-1} \text {, }
$$

respectively (Patterson et al., 1980; Watts and Dexter, 1997). This shows that the specific energies involved in the determination of RDC by this method and in primary tillage in the field fall in the same range of values.

Basic information about the 18 soils used is given in Table 1. It can be seen that none of the soils is sodic and therefore that we can ignore chemical dispersion and we can focus on mechanically-dispersed clay (MDC), only.

Experimental values of turbidity, $T$, as a function of the

\begin{tabular}{|c|c|c|c|c|c|c|}
\hline \multirow{2}{*}{$\begin{array}{l}\text { Profile } \\
\text { number }\end{array}$} & \multicolumn{3}{|c|}{ Eq. (9) } & \multicolumn{3}{|c|}{ Eq. (10) } \\
\hline & $\mathrm{a}$ & $\mathrm{b}$ & $\mathrm{r}$ & $\mathrm{c}$ & $\mathrm{d}$ & $\mathrm{r}$ \\
\hline 35 & $-4.889 \pm 2.599$ & $7.539 \pm 1.021$ & 0.982 & $0.000 \pm 0.000$ & $3.791 \pm 0.046$ & 1.000 \\
\hline 37 & $0.092 \pm 0.133$ & $0.678 \pm 0.052$ & 0.994 & $0.346 \pm 0.056$ & $0.384 \pm 0.014$ & 0.998 \\
\hline 85 & $0.191 \pm 0.049$ & $0.155 \pm 0.019$ & 0.985 & $0.259 \pm 0.070$ & $0.085 \pm 0.018$ & 0.958 \\
\hline 89 & $-0.440 \pm 0.546$ & $3.278 \pm 0.214$ & 0.995 & $0.966 \pm 1.168$ & $1.808 \pm 0.302$ & 0.973 \\
\hline 171 & $0.500 \pm 0.275$ & $0.511 \pm 0.108$ & 0.958 & $0.676 \pm 0.179$ & $0.294 \pm 0.076$ & 0.976 \\
\hline 173 & $1.302 \pm 0.484$ & $0.639 \pm 0.190$ & 0.922 & $1.643 \pm 0.558$ & $0.334 \pm 0.144$ & 0.854 \\
\hline 75 & $1.226 \pm 0.134$ & $0.740 \pm 0.053$ & 0.995 & $1.549 \pm 0.286$ & $0.406 \pm 0.074$ & 0.969 \\
\hline 145 & $0.300 \pm 0.094$ & $0.523 \pm 0.037$ & 0.995 & $0.507 \pm 0.125$ & $0.293 \pm 0.032$ & 0.988 \\
\hline 147 & $1.263 \pm 0.978$ & $2.435 \pm 0.384$ & 0.976 & $2.389 \pm 1.339$ & $1.320 \pm 0.346$ & 0.950 \\
\hline 149 & $0.432 \pm 0.082$ & $0.162 \pm 0.032$ & 0.962 & $0.488 \pm 0.053$ & $0.093 \pm 0.014$ & 0.979 \\
\hline 151 & $-3.506 \pm 1.508$ & $5.365 \pm 0.620$ & 0.987 & $0.000 \pm 0.000$ & $2.691 \pm 0.033$ & 1.000 \\
\hline 153 & $-2.873 \pm 0.479$ & $0.206 \pm 0.188$ & 0.614 & $3.037 \pm 0.453$ & $0.093 \pm 0.117$ & 0.491 \\
\hline 155 & $0.357 \pm 0.018$ & $0.109 \pm 0.007$ & 0.996 & $0.404 \pm 0.060$ & $0.007 \pm 0.002$ & 0.973 \\
\hline 157 & $1.025 \pm 0.040$ & $0.107 \pm 0.016$ & 0.979 & $1.064 \pm 0.025$ & $0.061 \pm 0.006$ & 0.989 \\
\hline 161 & $1.606 \pm 0.498$ & $0.125 \pm 0.196$ & 0.411 & $1.719 \pm 0.446$ & $0.052 \pm 0.115$ & 0.306 \\
\hline 163 & $1.185 \pm 0.070$ & $0.045 \pm 0.127$ & 0.756 & $1.192 \pm 0.050$ & $0.028 \pm 0.013$ & 0.837 \\
\hline 271 & $0.773 \pm 0.208$ & $0.352 \pm 0.082$ & 0.950 & $0.891 \pm 0.137$ & $0.203 \pm 0.035$ & 0.971 \\
\hline 273 & $0.380 \pm 0.093$ & $0.165 \pm 0.037$ & 0.954 & $0.459 \pm 0.112$ & $0.089 \pm 0.029$ & 0.909 \\
\hline
\end{tabular}
number of inversions, $N$, are given in Table 2 . The experimental results given in Table 2 were fitted to two different equations:

T a b l e 3. Fitted parameters for Eqs. (9) and (10). We identify parameter c with the spontaneously-dispersible clay (SDC) 
and

$$
T=a+b \ln (N)
$$

$$
T=c+d N^{0.5} .
$$

Equations (9) and (10) were fitted by linear regression, and the resulting parameters and values of the regression coefficients are presented in Table 3. Typical results are shown in Fig. 1, which also shows the values of RDC (with $N=4$ ) and the predicted value of SDC. Equation (9) provides a good fit over the experimental range $4<\mathrm{N}<32$, however the equation does not permit extrapolation to zero energy input $(N=0)$, for which it predicts $T=-\infty$, which is physically not realistic.

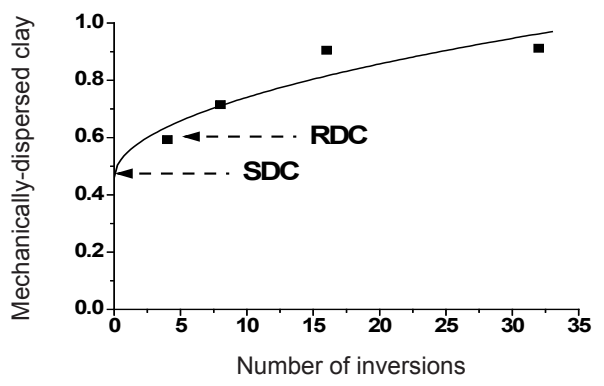

Fig. 1. Mechanically-dispersed clay (MDC) in suspension as a function of mechanical energy input (as measured by the number of inversions, $N$ ). The graph shows experimental points and the fitted curve from Eq. (10). Values of readily-dispersible clay (RDC) and the predicted value of spontaneously-dispersible clay (SDC) are indicated by arrows.

The first term in Eq. (10) is the value when $N=0$ and the turbidity $T=c$, which we identify with the content of SDC. When the predicted value of $\mathrm{c}$ was negative which is physically not realistic, we set $c=0$ and recalculated $d$. We believe that the cause was natural variation of soil properties, The second term in Eq. (10) gives the increase in the amount of mechanically-dispersed clay in suspension as a function of $N$. The resulting fitted values are given in Table 3.

It can be seen from the regression coefficients, $r$, in Table 3, that the fits of Eqs (9) and (10) are generally good. Exceptions are for soil profiles 153 and 161, for which the fits are very poor. The reason(s) remain unknown.

The values of RDC given in Table 2 for $N=4$, were correlated with the corresponding gravimetric water contents, $w$, given in Table 1. The regression equation obtained is:

$$
\mathrm{RDC}=-1.47( \pm 0.85)+0.25 w( \pm 0.06), r=0.72,
$$

We can compare the values of RDC with the predicted values of SDC given by the parameter $c$ of Eq. (10) given in Table 3. The SDC shows no correlation with any of the soil properties given in Table 1 except for the sample water con-

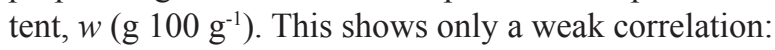

$$
\mathrm{SDC}=-0.37( \pm 0.65)+0.12 w( \pm 0.05), r=0.53,
$$

Equations (11) and (12) illustrate the large and dominating effect of water on the behaviour of clay and hence of soil. It is important to remember that $\mathrm{w}$ is the water content at which the soil has been stored in contrast to the saturated condition under which the dispersed clay is measured. This suggests that the soil is exhibiting a memory of its storage conditions and that this is governing its subsequent behaviour. This could occur if the soil colloids (ie the clay) have shrunk during storage. We do not know under what conditions such shrinkage is reversible or irreversible. Even if it is reversible, a significant time may be required for re-swelling to occur in the presence of free water. Further research is needed to determine this.

Neither Eq. (9) nor Eq. (10) enables prediction of the amount of clay dispersed as $N \rightarrow \infty$. Logically, we would expect this to trend towards the total clay content of the soil, $T C$, as given in Table 1. This hypothesis needs to be tested.

We suggest that future work should incorporate several improvements:

- the use of additional numbers of bottle inversions (for example $N=3$ and $N=5$ ) to give additional degrees of freedom which would enable Eq. (10) to be further developed and better evaluated;

- the use of bathing solutions with a range of electrolyte concentrations to enable the measurements of spontaneously-dispersed and readily-dispersed clay to be better related to observed soil behaviour in the field.

\section{CONCLUSIONS}

1. The objective method proposed for quantifying the amount of spontaneously-dispersed clay represents a considerable improvement over qualitative, observational methods based on the Emerson test.

2. Regressions show that the contents of readily- and spontaneously-dispersible clay are positively- correlated with the water contents at which the soil samples have been stored.

3. The results presented here support the conclusion from previous work that clay dispersion, as measured by suspension turbidity, is a sensitive indicator of soil stability in water which is important for the environment.

4. Given the importance of soil water content and the hydraulic history (history of wetting and drying) on soil physical properties (including clay dispersion), we recommend that effort should be put into developing methods for integrating this history so that it can be better taken into account in the study and prediction of soil properties and behaviour. In particular, it seems to be especially important to include a measure of the intensity of dryness attained by soil during its most recent dry period.

5. The results illustrate how soil samples must not be allowed to dry during storage. If it is required to study the physical or mechanical behaviour of soil as it was in the field, then soil samples must be stored at field water content. 


\section{REFERENCES}

AS, 2006. Methods for testing soils for engineering purposes. Standards Australia, Sydney, NSW 2000, Australia.

ASTM, 2014. Standard test methods for determining dispersion characteristics of clayey soils by the crumb test. ASTM International, West Conshohocken, PA, USA.

Brubaker B.C., Holzhey C.S., and Brasher B.R., 1992. Estimating the water-dispersible clay content in soils. Soil Sci. Soc. Am. J., 56(4), 1226-1232.

Caron J., Kay B.D., and Stone J.A.,1992. Improvement of structural stability of clay loam with drying. Soil Sci. Soc. Am. J., 56(5), 1583-1590.

Chan K.Y., 1989. Effect of tillage on aggregate strength and aggregation of vertisols. Soil Till. Res., 13, 163-175.

Czyż E.A. and Dexter A.R., 2009. Soil physical properties as affected by traditional, reduced and no-tillage for winter wheat. Int. Agrophysics, 23, 319-326.

Czyż E A. and Dexter A.R., 2011. Turbidity. In: Encyclopedia of Agrophysics (Eds J. Gliński, J. Horabik, and J. Lipiec), Springer Science, Dordrecht, The Netherlands, 938-940.

Czyż E.A., Dexter A.R., and Gațe O.P., 2010. Determination of soil stability in relation to ecological agriculture. In: Selected Problems of Soil Tillage Systems and Operations (Eds P.F. Borowski, M. Klimkiewicz and M.J. Powalka), Warsaw University of Life Sciences, WEMA Press, Warsaw, Poland.

Czyż E.A., Dexter A.R., and Terelak H., 2002. Content of readily-dispersible clay in some Polish soils. In: Sustainable Land Management - Environmental Protection (Eds M. Pagliai, R. Jones), Advances in Geoecology, 35, 115-124.

Czyż E.A. and Vizitiu O.P., 2012. Soil physical quality in relation to readily-dispersible clay, friability and saturated hydraulic conductivity. In: Practical Applications of Environmental Research (Eds J. Kostecka, J. Kaniuczak), Science for Economy, University of Rzeszów, Poland.

Dagesse D.F., 2013. Freezing cycle effects on water stability of soil aggregates. Can. J. Soil Sci., 93(4), 473-483.

Dexter A.R. and Czyż E.A., 2000a. Effects of soil management on the dispersibility of clay in a sandy soil. Int. Agrophysics, 14, 269-272.

Dexter A.R. and Czyż E.A., 2000b. Clay content of drainage water as affected by soil factors (Eds W.D. Reynolds, C.F. Drury, C.S. Tan). Proc. 4th EasternAugust 23-25, Leamington, Ontario, Canada.

Dexter A.R., Richard G., Czyż E.A., Davy J., Hardy M., and Duval O., 2011. Clay dispersion from soil as a function of antecedent water potential. Soil Sci. Soc. Am. J., 75, 444-455.
Dexter A.R. and Watts C.W., 2000. Tensile strength and friability. In: Soil and Environmental Analysis: Physical Methods, (Eds K.A. Smith, C.E. Mullins). Dekker Press, New York, USA.

Emerson W.W., 1967. A classification of soil aggregates based on their coherence in water. Aust. J. Soil Res., 5, 47-57.

Gațe O.P., Czyż E.A., and Dexter A.R., 2004. Effects of readily-dispersible clay on soil quality and root growth. In: Plant Growth in Relation to Soil Physical Conditions (Eds J. Lipiec, R. Walczak, G. Józefaciuk), Institute of Agrophysics Polish Academy of Science, Lublin, Poland.

Kay B.D. and Dexter A.R., 1992. The influence of dispersible clay and wetting/drying cycles on the tensile strength of a red-brown earth. Aust. J. Soil Res., 30, 297-310.

Loveday J. and Pyle J., 1973. The Emerson dispersion test and its relationship to hydraulic conductivity. Division of Soils Technical Paper, CSIRO, Melbourne, Australia.

Patterson D.E., Chamen W.C.T., and Richardson C.D., 1980. Long-term experiments with tillage systems to improve the economy of cultivations for cereals. J. Agric. Eng. Res., 25, $1-36$.

Quirk J.P., 1986. Soil permeability in relation to sodicity and salinity. Phil. Trans. Roy. Soc. Lond., A316, 297-317.

Shanmuganathan R.T. and Oades J.M., 1982. Effect of dispersible clay on the physical properties of the B horizon of a redbrown earth. Aust. J. Soil Res., 20, 315-324.

Vizitiu O., Czyż E.A., and Dexter A.R., 2010. Soil Physical Quality - Theory and Applications for Arable Soils. SITECH, Craiova, Romania.

Watts C.W. and Dexter A.R., 1997. The influence of organic matter in reducing the destabilization of soil by simulated tillage. Soil Till. Res., 42, 253-275.

Watts C.W., Dexter A.R., Dumitru E., and Arvidsson J., 1996a. An assessment of the vulnerability of soil structure to destabilization during tillage. Part I. A laboratory test. Soil Till. Res., 37, 161-174.

Watts C.W., Dexter A.R., Dumitru E., and Canarache A., 1996b. Structural stability of two Romanian soils as influenced by management practices. Land Degradation Develop., 7, 217-238.

Watts C.W., Dexter A.R., and Longstaff D.J., 1996c. An assessment of the vulnerability of soil structure to destabilization during tillage. Part II - Field trials. Soil Till. Res., 37, 175-190. 